\title{
Las facultades reglamentarias de la Agencia Nacional de Contratación Pública Colombia Compra Eficiente $^{1}$
}

Jorge Santos Rodríguez ${ }^{2}$

\section{RESUMEN}

El presente escrito examina la reciente sentencia del Consejo de Estado, a propósito de las funciones de Colombia Compra Eficiente en materia normativa y la posibilidad de regular administrativamente la materia contractual, con el fin de determinar si los manuales, guías y circulares que emite esta agencia pueden ser o no entendidos como verdaderas expresiones normativas, esto es, como actos administrativos reglamentarios de imperativos cumplimiento.

Palabras clave: Colombia Compra Eficiente, Consejo de Estado, Manuales, Circulares, Potestad reglamentaria, Facultades normativas.

1 Comentarios a Consejo de Estado, Sala de lo Contencioso Administrativo, Sección Tercera, Subsección C, del 16 de agosto de 2017, expediente 11001-03-26-000-2016-0001600(56166).

2 Docente investigador del Departamento de Derecho Administrativo Universidad Externado de Colombia, Bogotá, Colombia. Correo-e: jorge.santos@uexternado.edu.co.Para citar el artículo: Santos RodrígueZ, Jorge. Las facultades reglamentarias de la Agencia Nacional de Contratación Pública Colombia Compara Eficiente. Revista digital de Derecho administrativo, n. ${ }^{\circ}$ 19, primer semestre, Universidad Externado de Colombia, 2018, pp. 341-347. DOI: https://doi.org/10.18601/21452946.n19.14 


\title{
Regulatory Powers of the National Agency Colombia Compra Eficiente
}

\begin{abstract}
This paper examines a recent decision by the State Council, in the matter of the regulatory powers of Colombia Compra Eficiente and its competence for issuing administrative rules in the subject of public procurement; in order to assess whether the manuals, guides and directives of this agency are formal or informal rules.
\end{abstract}

Keywords: Colombia Compra Eficiente, State Council, Manuals, Guides, Directives, Regulatory Power, Formal Rulemaking, Informal Rulemaking.

1.- El artículo 2.2.1.2.1.2.9 del Decreto 1082 de 2015 faculta a la Agencia Nacional de Contratación Pública Colombia Compra Eficiente para disponer la forma en que las entidades estatales de la rama ejecutiva del poder público, a nivel nacional, deben dar, suscribir y hacer uso de los acuerdos marco de precios que celebre dicha entidad para la adquisición de bienes y servicios de características técnicas uniformes y de común utilización.

En la sentencia objeto de comentario se estudió una demanda de nulidad simple respecto del mencionado artículo, la cual se basó en que el contenido del acto acusado implicaba que el Gobierno Nacional no estaba reglamentando la selección abreviada para bienes y servicios de características técnicas uniformes y de común utilización, sino que había trasladado el ejercicio de esa competencia a Colombia Compra Eficiente, situación que se agravaba con el hecho de que la competencia se hubiera ejercido por medio de un manual y no de una circular.

Para resolver la pretensión de nulidad, el Consejo de Estado hizo algunas reflexiones conceptuales y teóricas respecto a la potestad reglamentaria, las bases constitucionales de la libertad de empresa y la libre competencia, los fines constitucionales de la contratación estatal y el sometimiento de la administración a los fines y valores constitucionales, y la contratación con arreglo a los acuerdos marco de precios, para con base en ello concluir que "Colombia Compra Eficiente cuenta con competencias legales de diseño, organización y celebración de los Acuerdos Marco de Precios, lo que le habilita para establecer las condiciones logísticas, operacionales y jurídicas para la ejecución de la figura, no siendo ejercicio de potestad reglamentaria de la Ley sino regulación administrativa para la ejecución cumplida del Acuerdo Marco, como negocio jurídico, competencia, subordinada a la Ley y al reglamento", lo que permitió negar la pretensión de nulidad incoada. 
2.- Ahora bien, más allá de la decisión que parece ser acertada de cara a lo previsto en el parágrafo $5 .^{\circ}$ del artículo $2 .^{\circ}$ de la Ley 1150 de 2007 y en el artículo 2. ${ }^{\circ}$ del Decreto Ley 4170 de 2011, resultan particularmente interesantes las consideraciones del Consejo de Estado respecto del alcance de las competencias reglamentarias o de regulación administrativa atribuidas legalmente a Colombia Compra Eficiente.

En ese sentido, afirma el Consejo de Estado, con cita de su propia jurisprudencia-que no se refiere exactamente el punto-, que "la potestad reglamentaria puede ser trasladada o reconocida a otros organismos de la Administración a través de la expedición de actos generales para cumplir o hacer cumplir la ley", lo cual, atado al entendimiento que tiene la sentencia sobre las competencias de formulación de políticas públicas y de desarrollo o impulso de herramientas en materia de compras públicas, permite inferir que en el caso concreto de Colombia Compra Eficiente es perfectamente posible que la ley le atribuya directamente la posibilidad de expedir actos administrativos de carácter general que regulen o reglamenten diversos aspectos en materia de contratación estatal, o aun que sea directamente el presidente de la República quien le atribuya la función de expedir normas de carácter general, en concordancia con la competencias generales atribuidas por la ley.

3.- Esas afirmaciones de la jurisprudencia del Consejo de Estado podrían llegar a hacer pensar-pues lo cierto es que la sentencia no lo dice expresamente-que las potestades legalmente atribuidas a Colombia Compra Eficiente dan lugar a la expedición de actos administrativos de carácter general y, por lo mismo, aunque sometidos a la Constitución, la ley y los reglamentos, manuales, circulares y guías que comúnmente expide la mencionada entidad resultarían de obligatorio cumplimiento tanto para ella misma, como para demás los partícipes en la contratación pública: entidades estatales, contratistas, proponentes, etc.

Bajo ese entendimiento de la sentencia objeto de comentario, las competencias de Colombia Compra Eficiente resultarían ser materialmente similares a las que legalmente se le han atribuido a las comisiones de regulación de servicios públicos en el sentido de que permiten la expedición de actos administrativos obligatorios, pero de categoría inferior a los reglamentos, conclusión que pareciera discutible de cara a lo que resulta del análisis de las normas de carácter legal que le atribuyen competencia a Colombia Compra Eficiente y, en particular, de lo previsto en el Decreto Ley 4170 de 2011, más aún cuando muchas de las competencias que realmente ejerce no se desprenden directamente de esas normas de categoría legal, sino de normas de carácter reglamentario.

4.- En efecto, como bien lo han dicho las jurisprudencias constitucional y administrativa -citadas incluso en la sentencia objeto de comentario-, la competencia de reglamentación no corresponde de forma exclusiva y excluyente al presidente de la República en ejercicio de la potestad reglamentaria consagrada 
en el artículo 189.11 de la Constitución Política, sino que se extiende también a otros órganos constitucionales respecto de los cuales existe una habilitación expresa por parte de la Constitución Política para reglamentar asuntos puntuales igualmente dispuestos en el texto constitucional (Consejo Superior de la Judicatura, art. 257-3, Consejo Nacional Electoral, art. 265-9; Junta Directiva del Banco de la República, art. 371; Contraloría General de la República y contralorías territoriales, art. 268-12; y Contador General, art. 354)33.

Además, según las mismas jurisprudencias constitucional y administrativa -también citadas en la sentencia materia de comentario-, con base en el artículo 208 de la Constitución Política, los ministerios también tienen la posibilidad de expedir actos administrativos de carácter general, de manera semejante a una reglamentación, siempre y cuando una ley le atribuya de manera precisa dicha competencia. Incluso, dicha consideración ha sido extendida a otras autoridades administrativas diferentes a los ministerios a las que también se les ha reconocido que gozan de una especie de potestad reglamentaria, pero bajo la condición de que lo hagan previa autorización de la ley o de norma con fuerza de ley, de tal manera que no existe una potestad general y autónoma para los órganos administrativos de expedir normas reglamentarias, sino que se requiere siempre de autorización legal y las normas que se produzcan estarán subordinadas, incluso, a los actos reglamentarios del presidente de la República ${ }^{4}$.

5.- Dentro de ese marco, es preciso determinar si existe alguna disposición con fuerza de ley que establezca, directa o indirectamente, una competencia reglamentaria o regulatoria a cargo de Colombia Compra Eficiente. En ese sentido, en primer lugar, es necesario acudir al Decreto Ley 4170 de 2011 que es la norma orgánica de la mencionada agencia.

Al respecto, el Decreto Ley 4170 de 2011, en sus considerandos, señala que la motivación de la creación de Colombia Compra Eficiente es contar con un "organismo técnico especializado que se encargue de impulsar políticas, normas y unificar procesos en materia de compras y contratación pública, preparar

3 Cfr. Libardo Rodríguez Rodríguez. "Los reglamentos autónomos", en Memorias vi Foro Iberoamericano de Derecho Administrativo y VIII Jornadas de Derecho Constitucional y Administrativo, Bogotá, Universidad Externado de Colombia, 2007, pp. 946-951, con cita de abundante jurisprudencia que explica el funcionamiento de cada uno de los casos mencionados.

4 Cfr. Jorge EnRiQue IbáÑ̃z NAJAR. "Alcance y límites de la potestad reguladora y reglamentaria", en Revista Vniversitas, n. ${ }^{\circ}$ 106, diciembre de 2003, Bogotá, Pontificia Universidad Javeriana, pp. 9 y ss. Igualmente, Corte Constitucional, Sentencia C-782 de 2007: "No obstante, ha sostenido la jurisprudencia constitucional, que la potestad reglamentaria no es exclusiva del Presidente de la República, por cuanto puede ser ejercida de igual forma por otros órganos y funcionarios del Estado, en materias de orden técnico o especializado dentro de sus respectivas competencias, por expresa atribución legal y, teniendo un carácter residual o subordinado frente a la potestad presidencial". 
y suscribir los acuerdos marco de precios [...] y articular los partícipes de los procesos de compras y contratación pública". Como se ve, la mencionada entidad no fue concebida como un ente creador de normas, sino que fue pensado para "impulsar" normas, lo cual significa que su función es hacer proyectos normativos, sin que ello implique que pueda efectivamente crear nuevas normas jurídicas.

En concordancia con esa concepción general de la función de Colombia Compra Eficiente, el artículo 2. ${ }^{\circ}$ del Decreto Ley 4170 de 2011, al señalar los objetivos de dicha entidad, dispone que "como ente rector, tiene como objetivo desarrollar e impulsar políticas públicas y berramientas, orientadas a la organización y articulación de los partícipes en los procesos de compras y contratación pública con el fin de lograr una mayor eficiencia, transparencia y optimización de los recursos del Estado". Como puede verse, dentro de los objetivos de la entidad -como también lo destacó el Consejo de Estado en la sentencia que se comenta-se encuentra simplemente el del desarrollo e impulso de políticas públicas y el de creación de herramientas que permitan la organización y articulación de los partícipes. Sobre el particular, debe señalarse que es evidente que el impulso a las políticas públicas en materia de compras y contratación pública no permite la expedición de normas jurídicas, sino simplemente la participación en la elaboración de mejores prácticas y la proposición de nuevas normas con las finalidades mencionadas en la norma, a efectos de que sean adoptadas por los órganos competentes. A su vez, el desarrollo de herramientas en materia de compras y contratación pública permite a Colombia Compra Eficiente la creación de instrumentos que permitan una mejor comprensión y aplicación de las normas existentes, lo cual asemeja en mayor medida su función a una de carácter consultivo y no a una de carácter imperativo ${ }^{5}$.

Finalmente, en cuanto a las funciones específicas señaladas a Colombia Compra Eficiente fijadas en el artículo 3. ${ }^{\circ}$ del Decreto Ley 4170 de 2011 se encuentran, entre otras, las de: i) "proponer al Gobierno Nacional las políticas públicas, planes, programas y normas en materia de compras y contratación pública" (num. 1), la cual corrobora que su competencia solo se extiende a la elaboración de proyectos de normas; ii) "Desarrollar, implementar y difundir las políticas públicas, planes, programas, normas, instrumentos y berramientas que faciliten las compras y contratación pública del Estado" (num. 2), función que debe ser entendida en el sentido de que Colombia Compra Eficiente simplemente adopta medidas prácticas que permitan dar eficacia a las normas en materia de contratación, y difunde, esto es, da a conocer, dichas normas, y iii) "Difundir las normas, reglas,

5 En ese sentido, cfr. Felipe de Vivero ArCiniegas. "Las funciones de consulta y expedición de circulares asignadas a la Agencia Nacional de Contratación en el marco de la entrada en vigencia del nuevo Código de Procedimiento Administrativo y de lo Contencioso Administrativo", en Juan Carlos Cassagne (dir.). Tratado general de los contratos públicos, Buenos Aires, La Ley, 2013, pp.1175 y ss. 
procedimientos, medios tecnológicos y mejores prácticas para las compras y la contratación pública, y promover y adelantar con el apoyo y coordinación de otras entidades públicas cuyo objeto se los permita, la capacitación que considere necesaria" (num. 10), función que ratifica que simplemente a Colombia Compra Eficiente se le atribuyó una función de difusión normativa y no de creación.

Así las cosas, en el análisis de la norma orgánica de Colombia Compra Eficiente se evidencia que sus funciones en materia normativa no incluyen la competencia de regular administrativamente la materia contractual, sino que se limitan a proponer nuevas normas y a crear instrumentos que permitan la mejor aplicación de las normas sobre contratación y compras públicas vigentes.

6.- De otra parte, en cuanto a la atribución indirecta de competencias normativas, es preciso hacer notar que no se conoce dentro de las reglas legales aplicables a la contratación pública alguna que establezca que el órgano rector o que Colombia Compra Eficiente pudiera desarrollar, con efectos imperativos, algún aspecto de la ley, de tal manera que desde ese punto de vista no puede decirse que exista una atribución indirecta de competencias.

Ahora bien, como se explicó antes, para que una autoridad administrativa diferente del presidente de la República goce de una especie de potestad reglamentaria, es necesario que la Constitución Política o una norma con fuerza de ley le atribuyan expresamente esa competencia, lo cual significa que la misma no puede tener origen en normas de carácter reglamentario. Por ello, cuando el Decreto 1082 de 2015 atribuye a Colombia Compra Eficiente diversas clases de funciones que parecieran tener un carácter normativo -por ejemplo, los manuales y guías para la evaluación del riesgo que prevé el artículo 2.2.1.1.1.6.3-, ellas deben ser entendidas en el contexto general de las competencias; esto es, como meros instrumentos prácticos que permiten a los partícipes del sistema de contratación y compras públicas llevar a cabo sus tareas de mejor manera.

7.- Por ello, los manuales, guías y circulares que emite Colombia Compra Eficiente no pueden ser entendidos como verdaderas expresiones normativas - esto es, no pueden ser vistos como actos administrativos reglamentarios de imperativos cumplimiento-, sino simplemente como instrumentos o herramientas que permiten a las entidades estatales, los proponentes, los contratistas, los órganos de control y demás interesados poder dar aplicación de manera más simple a las normas de contratación y compras públicas, a la vez que permiten garantizar una mayor eficacia de tales normas.

Así las cosas, dichos documentos publicados por Colombia Compra Eficiente no solo no tienen un carácter obligatorio, como lo ha reconocido un sector 
de la jurisprudencia ${ }^{6}$ y de la doctrina ${ }^{7}$, sino que ni siquiera puede reconocerse que tienen un contenido normativo; esto es, no se trata de ninguna clase de normas jurídicas, sino simplemente de instrumentos, herramientas o prácticas que buscan hacer mejor la contratación estatal.

8.- Por último, el hecho de que el Consejo de Estado haya sistemáticamente admitido las demandas presentadas contra manuales, guías y circulares de Colombia Compra Eficiente haya adoptado medidas cautelares respecto de documentos emitidos por dicha entidad, y haya resuelto de fondo pretensiones de nulidad contra tales documentos, no implica, desde ningún punto de vista, que se trata de actos administrativos de carácter general con eficacia vinculante.

Al respecto, debe recordarse que, desde el año 2014, el Consejo de Estado ha venido sosteniendo que sin importar si las circulares, oficios o documentos emitidos por la administración son o no vinculantes, ellas gozan de control judicial ${ }^{8}$, de tal manera que el mero hecho de que haya existido un control judicial respecto de los manuales, guías y circulares de Colombia Compra Eficiente por parte del Consejo de Estado no implica un reconocimiento de su carácter vinculante, sino simplemente la aplicación de la idea de que no existe actuación administrativa que se resista al control judicial.

En efecto, gracias a los garantistas avances de la jurisprudencia, actualmente no es posible que una autoridad administrativa intente modificar, a través de actos "informales" o de soft law, las normas vigentes, para evitar el rigor de la protección judicial frente a sus actuaciones contrarias a derecho. Así, las actuaciones judiciales en contra de los documentos de Colombia Compra no pueden ser vistos como admisión de su carácter vinculante, sino como una expresión de garantía del principio de legalidad por parte de la jurisdicción administrativa.

6 Cfr. Corte Constitucional, Sentencia C-004 de 2017

7 Cfr. Héctor Santaella Quintero. "El doble nivel, vinculante y no vinculante, de la reglamentación en la contratación pública en Colombia", en Alberto Montaña Plata y Jorge IvÁN RINCÓN CÓRDOBA (eds.). Contratos públicos: Problemas, perspectivas y prospectivas. XVIII Jornadas Internacionales de Derecho Administrativo, Bogotá, Universidad Externado de Colombia, 2017, pp. 785 y ss.

8 Cfr. Consejo de Estado, Sala de lo Contencioso Administrativo, Sección Primera, sentencia del 27 de noviembre de 2014, expediente 05001-23-33-000-2012-00533-01. 